09,03

\title{
Фотоиндуцированные эффекты в спектрах люминесценции ZnO
}

\author{
( И.Х. Акопян, М.Э. Лабзовская, Б.В. Новиков, А.А. Лисаченко, А.Ю. Серов, Н.Г. Философов \\ Санкт-Петербургский государственный университет, \\ Санкт-Петербург, Россия \\ E-mail: xrul@mail.ru
}

(Поступила в Редакцию 5 июля 2017 г.)

Проведено исследование влияния интенсивного УФ-облучения на спектры фотолюминесценции (ФЛ) порошков и нанокристаллических пленок $\mathrm{ZnO}$, полученных методом атомного наслаивания (ALD). При комнатной температуре изучено поведение спектров при непрерывном облучении УФ-светом в многократных циклах вакуум-атмосфера. Обсуждены изменения интенсивностей экситонного излучения и излучения в области „зеленой“ полосы, связанные с явлениями фотодесорбции и фотоадсорбции кислорода. В температурном диапазоне 5-300 K изучено влияние сильного УФ-облучения на спектр близкраевой люминесценции пленок ZnO. Обсуждена природа новой линии, возникающей в ФЛ облученной пленки в области излучения связанных экситонов.

DOI: 10.21883/FTT.2018.02.45391.223

\section{1. Введение}

Экситонные и фононные состояния в оксиде цинка, востребованном материале для приборов УФ-оптоэлектроники, катализа, биомаркеров и др., изучены весьма подробно [1]. ZnO - прямозонный полупроводник с разрешенными переходами, в котором коэффициент поглощения в экситонных и зон-зонных переходах достигает значений $10^{5} \mathrm{~cm}^{-1}$ и более. При таких коэффициентах поглощения экситоны и носители тока образуются в приповерхностной области, и их поведение во многом определяется состоянием поверхности. Экситоны могут локализоваться на поверхностных центрах, на создаваемых неоднородным поверхностным полем флуктуациях потенциала, разрушаться в сильных электрических полях.

О локализации экситонов на поверхностных центрах акцепторного типа в полупроводниках $\mathrm{A}_{2} \mathrm{~B}_{6}$ впервые сообщалось в $[2,3]$. В низкотемпературных спектрах люминесценции монокристаллов $\mathrm{CdS}, \mathrm{CdSe}$ и $\mathrm{ZnO}$ наблюдалась полоса излучения, приписанная поверхностному экситону. В спектрах фотолюминесценции (ФЛ) тонких пленок и других наноструктур $\mathrm{ZnO}$ с развитой поверхностью при низких температурах полоса излучения поверхностного экситона (SX) может быть доминирующей структурой [4]. При интерпретации полосы SX в основном принимается модель, предложенная в $[3,4]$ - локализация экситонов в неоднородном потенциале, создаваемом акцептороподобными поверхностными центрами.

Большое внимание в исследованиях последних лет уделяется влиянию изменения состояния поверхности на ФЛ ZnO-наноструктур. Исследовано влияние диэлектрического $\mathrm{Al}_{2} \mathrm{O}_{3}$-покрытия [5] на спектры ФЛ нанопроволок $\mathrm{ZnO}$, в [6] изучено влияние высокотемпературных отжигов нанопроволок $\mathrm{ZnO}$ в вакууме и в кислородном потоке на экситонное излучение и излучение в области дефектной ,зеленой“ полосы (3П), в [7] - влияние кислорода и УФ-облучения на ФЛ суспензий нанокристаллических частиц $\mathrm{ZnO}$. Показано [5,6], что к увеличению интенсивности экситонного излучения и ослаблению ЗП в спектрах фотолюминесценции $\mathrm{ZnO}$ приводит уменьшение наклона электронных зон на поверхности. В нашей работе [8] установлено возгорание экситонной люминесценции после высокотемпературного прогрева пленок $\mathrm{ZnO}$ в атмосфере водорода и окиси углерода. Тот же эффект усиления экситонной ФЛ наблюдался нами при фотодесорбции в вакууме при облучении порошка $\mathrm{ZnO}$ светом из области собственного поглощения $(\lambda=325 \mathrm{~nm})$. Во всех случаях эффект гасился после напуска кислорода. Удаление кислорода с поверхности $\mathrm{ZnO}$ в наших работах контролировалось масс-спектрометрически.

В настоящей работе мы продолжаем изучение процессов десорбции в $\mathrm{ZnO}$. При комнатной температуре исследовано поведение экситонной люминесценции и излучения в области ЗП в порошках и пленках $\mathrm{ZnO}$ при чередовании циклов атмосфера-вакуум при непрерывном УФ-облучении. При низких температурах (5-120 K) изучается влияние сильного УФ-облучения на ФЛ пленок $\mathrm{ZnO}$ в области излучения связанных экситонов. Обсуждается возможность возникновения новых и перезарядки существующих центров локализации и возможность образования при интенсивном облучении пленок $\mathrm{ZnO}$ связанных биэкситонов.

\section{2. Эксперимент}

Исследования фотолюминесценции проводились на образцах, помещенных в вакуумную камеру гелиевого криостата замкнутого цикла фирмы Janis Research Company. Образцы крепились на пальце хладопровода и могли охлаждаться до $T=5 \mathrm{~K}$. При комнатной температуре в вакуумной камере криостата давление могло быть понижено до $10^{-4}$ Torr. Фотолюминесцен- 
ция возбуждалась $\mathrm{He}-\mathrm{Cd}(\lambda=325 \mathrm{~nm}, W=10 \mathrm{~mW})$ и азотным $\left(\lambda=337 \mathrm{~nm}, W_{\mathrm{cp}}=105 \mathrm{~mW}\right.$ при частоте $1 \mathrm{kHz}$, длительность импульса $\sim 7 \mathrm{~ns}$ ) лазерами. Использовался двойной монохроматор МДР-204-2 фирмы Ломофотоника с дисперсией $25 \mathrm{~A} / \mathrm{mm}$. Объектами исследования были порошки и пленки $\mathrm{ZnO}$. Пленки различной толщины $(4 \mathrm{~nm}, 10$ и $40 \mathrm{~nm})$ были получены методом атомного наслаивания (ALD метод). Методы роста пленок, морфология и оптические спектры порошков и пленок описаны в наших работах $[8,9]$.

\section{3. Результаты и обсуждение}

На рис. 1 и 2 приведены результаты изучения при комнатной температуре изменения интенсивностей экситонного излучения (рис. 1) и излучения в области ЗП (рис. 2) порошка $\mathrm{ZnO}$ при непрерывном облучении образца светом из области собственного поглощения $(\lambda=325 \mathrm{~nm})$ при многократных изменениях газовой среды в криостате - последовательных циклах атмосфера-вакуум.

Из рис. 1 видно, что при вакуумировании образца интенсивность экситонной ФЛ увеличивается, при напуске атмосферы наблюдается резкое уменьшение величины сигнала экситонной ФЛ, за которым следует небольшой рост интенсивности. С каждым циклом амплитуды изменения интенсивности при смене среды становятся больше. Увеличение происходит симметрично и за счет усиления сигнала в вакууме, и за счет уменьшения его в атмосфере.

На рис. 2 представлены динамика изменения интенсивности излучения в максимуме „зеленой“ полосы в таких же циклах вакуум-атмосфера. В отличие от экситонного излучения интенсивность этой полосы уменьшается при откачке и увеличивается при напуске атмосферы. Кроме того, в каждом следующем цикле разность между интенсивностями ЗП в вакууме и атмосфере (в отличие от экситонного излучения) становится меньше, эффект максимален в первом цикле.

Указанные явления наблюдаются как на порошке $\mathrm{ZnO}$, так и на пленках. Насколько нам известно, данные о влиянии удаления кислорода с поверхности $\mathrm{ZnO}$ на спектры ФЛ очень скудны $[8,10,11]$. В [8] этот процесс контролировался масс-спектрометрически. В [10] наблюдалось падение интенсивностей и экситонной, и „зеленой“ полос излучения в ФЛ порошка $\mathrm{ZnO}$ при адсорбции кислорода с неполным восстановлением интенсивности при последующей откачке. Аналогичное влияние на ФЛ авторы [10] наблюдали и в экспериментах с водородом и окисью углерода, что также противоречит результатам в $[8]$.

Полученные в настоящей работе изменения экситонной люминесценции и излучения в области „зеленой“ полосы в циклах вакуум-атмосфера мы связываем с процессами фотодесорбции и фотоадсорбции кислорода, соответственно, исходя при этом из влияния загиба электронных зон в приповерхностной области на излучение

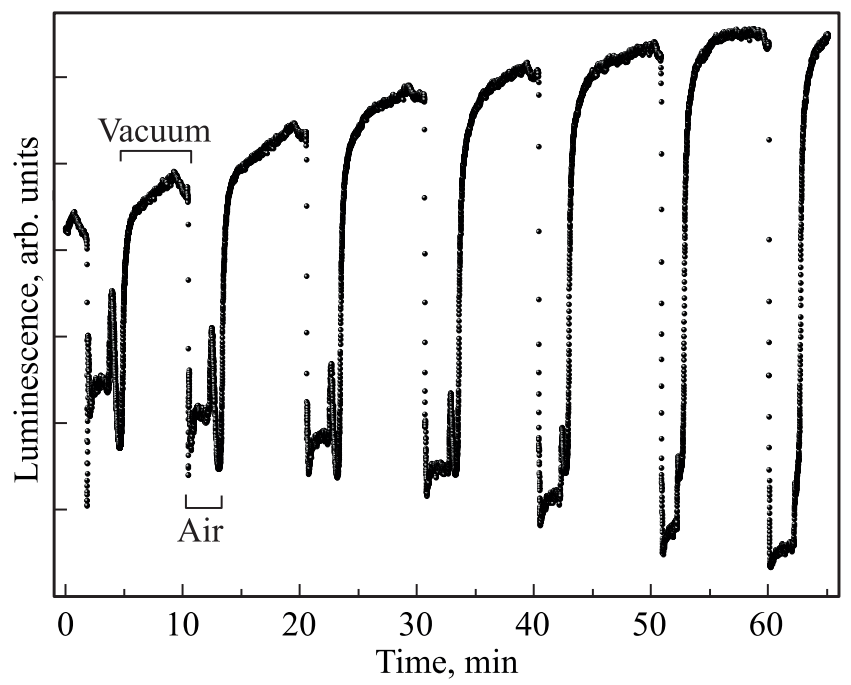

Рис. 1. Кинетика экситонного излучения порошка $\mathrm{ZnO}$ при $T=300 \mathrm{~K}$ и непрерывном облучении $\mathrm{He}-\mathrm{Cd}$-лазером. Приведены данные в последовательных циклах атмосфера-вакуум.

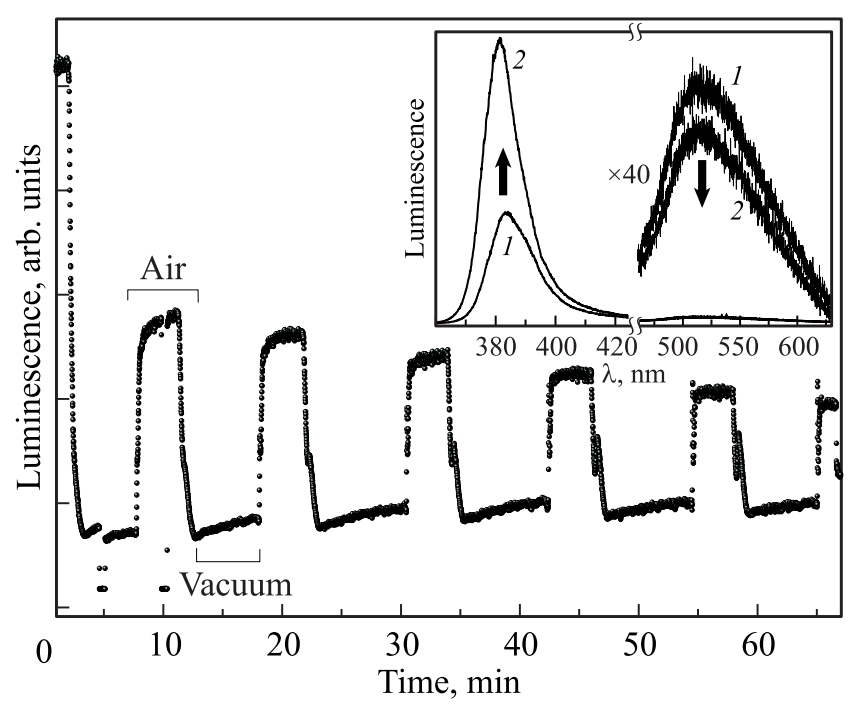

Рис. 2. Кинетика излучения порошка $\mathrm{ZnO}$ при $T=300 \mathrm{~K}$ в области максимума зеленой полосы при непрерывном облучении $\mathrm{He}-\mathrm{Cd}$-лазером. На вставке - пример изменений интенсивностей в спектре ФЛ в области максимума экситонного излучения $(\sim 383 \mathrm{~nm})$ и максимума излучения в ЗП $(\sim 510 \mathrm{~nm})$ при откачке в одном из циклов воздух (1)-вакуум (2).

в обеих полосах. Увеличение сигнала экситонной люминесценции и ослабление интенсивности ЗП естественно связываем с десорбцией кислорода, приводящей к спрямлению электронных зон на поверхности. Следствием уменьшения наклона зон является, с одной стороны, большее перекрытие волновых функций электронов и дырок и соответственно большая плотность экситонов в приповерхностной области, и, с другой стороны, уменьшение концентрации дырок, активирующих положительные однозарядные вакансии кислорода, участвующие в 
процессе излучения ЗП [5]. Адсорбция в атмосфере, способствующая увеличению загиба зон, приводит к обратным эффектам - ослаблению экситонной люминесценции и усилению ЗП, процессам, аналогичным наблюдаемым при отжигах образцов $\mathrm{ZnO}$ в кислородном потоке [6].

Результаты наших опытов по контролю фотодесорбции масс-спектрометрическими методами [8] показали, что на кривых нарастания экситонной ФЛ в вакууме в каждом цикле можно выделить быструю (s) и медленную (до полутора $\mathrm{min}$ ) компоненты.

Известно, что фотодесорбция кислорода в вакуум возможна из молекулярной $\left(\mathrm{O}_{2}^{-}\right)$и диссоциированной $\left(\mathrm{O}^{-}\right)$ форм кислорода [12]. Считаем, что быстрая фаза роста экситонной ФЛ связана с десорбцией относительно слабо связанного молекулярного кислорода, а медленная - c атомарным кислородом, характеризующимся более прочной связью, близкой к связи поверхностного структурного аниона.

С действием непрерывного УФ-облучения мы связываем также наблюдающиеся в каждом последующем цикле увеличение (по сравнению с предыдущим циклом) интенсивности экситонного излучения в вакууме и уменьшение интенсивности сигнала зеленой полосы в атмосфере после пребывания образца в вакууме. Увеличение интенсивности экситонной люминесценции под действием непрерывного УФ-облучения $\mathrm{He}-\mathrm{Cd}$ лазером в вакууме наблюдалось нами ранее в спектрах ФЛ-пленок $\mathrm{ZnO}$ при $T=5$ и $300 \mathrm{~K}$ [9]. Заметим, что при $T=5 \mathrm{~K}$ для $40 \mathrm{~nm}$ пленок увеличение интенсивности экситонного излучения под действием облучения $\mathrm{He}-\mathrm{Cd}$ лазером в вакууме наблюдалось в течение длительного времени (более $2 \mathrm{~h}$ ), не достигая насыщения.

Подобный эффект увеличения интенсивности экситонной люминесценции под действием УФ-облучения, сопровождающийся гашением ЗП, известен и в ФЛ коллоидных насыщенных азотом (т.е. в отсутствие кислорода) суспензий нанокристаллических $\mathrm{ZnO}$ частиц при комнатной температуре [7]. При этом показано, что скорость гашения максимальна в первые $5 \mathrm{~min}$, достигая через $\sim 30 \mathrm{~min}$ насыщения на уровне $\sim 0.1$ от исходной интенсивности. Заметим, что в характере изменения интенсивности излучения ЗП в циклах в ФЛ наших образцов (рис. 2) проявляются похожие черты.

Далее в настоящей работе анализируется влияние интенсивного УФ-облучения в вакууме на спектр близкраевой экситонной люминесценции пленок $\mathrm{ZnO}(d=4$ и $10 \mathrm{~nm})$ при $T=5 \mathrm{~K}$. Как известно [1], в низкотемпературной ФЛ объемных образцов и наноструктур $\mathrm{ZnO}$ при относительно низких уровнях возбуждения доминирующей структурой являются линии излучения экситонов, локализованных на нейтральных центрах. Спектр ФЛ изучаемых нами нанокристаллических пленок, полученных методом ALD, при $T=5 \mathrm{~K}$ и низ-

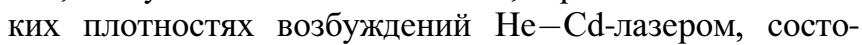
ит из слабо разрешенной полосы излучения экситонов на нейтральных донорах $(368.3-368.8 \mathrm{~nm})$ и полосы поверхностного экситона $(368.5 \mathrm{~nm})$. С ростом

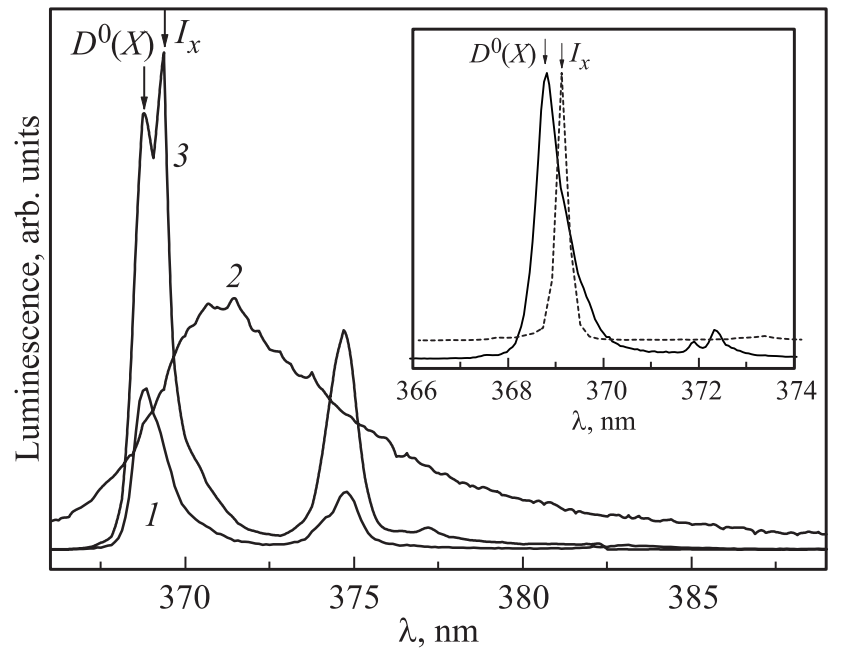

Рис. 3. Спектры ФЛ пленки $\mathrm{ZnO}(d=10 \mathrm{~nm})$ при $T=5 \mathrm{~K}$

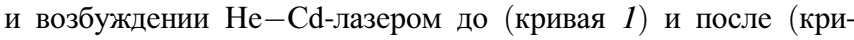
вая 3) облучения ее азотным лазером в течение $10 \mathrm{~min}$. Кривая 2 - Спектр ФЛ пленки при возбуждении азотным лазером. На вставке - спектры ФЛ пленки, полученной методом MBE, при $T=5 \mathrm{~K}$ и возбуждении $\mathrm{He}-\mathrm{Cd}$-лазером $\left(0.3 \mathrm{~kW} / \mathrm{cm}^{2}\right)$ до (сплошная кривая) и после (пунктир) облучения азотным лазером.

интенсивности возбуждения опережающий рост показывает линия $D^{0}(X)(368.8 \mathrm{~nm})$. При плотности возбуждения $\mathrm{He}-\mathrm{Cd}$-лазером $\sim 0.3 \mathrm{~kW} / \mathrm{cm}^{2}$ эта линия с полосой при $\sim 374.5 \mathrm{~nm}$ формирует спектр излучения пленок (рис. 3, кривая 1). Относительно природы полосы $374 \mathrm{~nm}(3.31 \mathrm{eV})$ в литературе нет единого мнения. Энергетическое положение полосы позволяет связывать ее с несколькими излучательными процессами, в частности, с излучением $1 L O$-свободного экситона [1], с переходом свободный электрон-акцептор [13-15], с излучением связанных экситонов, в локализованных на акцепторе $[16,17]$ с двухэлектронными процессами в излучении связанных экситонов [18] и др. Полоса наблюдается в широком температурном интервале от гелиевых до комнатных температур. При $T>80 \mathrm{~K}$ усиливается вклад в излучение в этой спектральной области $1 L O$-фононного повторения свободного экситона [13]. На рис. 3 представлено также изменение спектра ФЛ под действием мощного излучения азотным лазером. Кривая 2 - спектр ФЛ при плотности возбуждения $\sim 1 \mathrm{MW} / \mathrm{cm}^{2}$ азотным лазером, кривая $3-$ спектр ФЛ той же пленки при возбуждении $\mathrm{He}-\mathrm{Cd}$ лазером после облучения ее азотным лазером в течение $10 \mathrm{~min}$. При облучении азотным лазером спектр ФЛ (кривая 2) имеет вид широкой асимметричной полосы с максимумом $\sim 372 \mathrm{~nm}$, которую можно отнести к излучению электронно-дырочной плазмы [1]. Подчеркнем, что мощность возбуждения $\mathrm{He}-\mathrm{Cd}$-лазером до и после облучения пленки азотным лазером одинакова. Длительность облучения азотным лазером для разных образцов составляла 5-20 min. Видно, что в спектре 
облученной пленки (кривая 3) появляется новая узкая линия $I_{x}$ при $369.3 \mathrm{~nm}$. Кроме того, наблюдается изменение формы полосы и заметно увеличивается относительно связанного экситона $D^{0}(X)$ ее интенсивность. Эффект возникновения в спектре ФЛ линии $I_{x}$ в результате интенсивного УФ-облучения наблюдался нами и в пленках, полученных методом $\mathrm{MBE}$ на $\mathrm{Al}_{2} \mathrm{O}_{3}$ на подложке. Вставка на рис. 3 показывает приведенные спектры люминесценции МВЕ пленки $(d=420 \mathrm{~nm})$ до и после облучения ее азотным лазером.

При повышении температуры (рис. 4) интенсивность $I_{x}$ линии ослабевает, а при температурах более $120 \mathrm{~K}$ линия, как и $D^{0}(X)$, становится неразличимой. После пребывания облученной пленки при комнатной температуре в течение нескольких часов линия $I_{x}$ уже не наблюдается, однако может быть снова получена при интенсивном облучении образца при $T=5 \mathrm{~K}$.

Рис. 5 показывает зависимость интенсивности возникающей линии излучения от уровня возбуждения Не-Cd-лазера при $T=5 \mathrm{~K}$. Кривая 1 соответствует максимальной интенсивности $\left(0.3 \mathrm{~kW} / \mathrm{cm}^{2}\right)$, кривые $2-4$ получены при ослаблении возбуждения нейтральными фильтрами. При общем уменьшении интенсивности излучения интенсивность $I_{x}$ линии падает быстрее и на кривой 4 (при интенсивности возбуждения $\sim 0.05 I_{\max }$ ) она уже отсутствует. Кроме того, при ослаблении возбуждения максимум длинноволновой полосы смещается от 374.5 до $375.0 \mathrm{~nm}$.

Установлено, что линия $I_{x}$ возникает в спектре ФЛ пленок $\mathrm{ZnO}$ и при интенсивном импульсном возбуждении третьей гармоникой титан-сапфирового лазера $\left(\lambda_{\text {возб. }}=266 \mathrm{~nm}\right.$, максимальная мощность в импульсе $200 \mathrm{~W}$ ), при этом по интенсивности она может превосходить линию $D^{0}(X)$.

Спектральное положение линии $I_{x}(369.3 \mathrm{~nm})$ совпадает с одной из линий связанных на нейтральном доноре экситонов - линией $I_{9}$ в согласии с принятой в настоящее время системой обозначений связанных экситонов в $\mathrm{ZnO}$ [19]. Для $I_{9}$ энергия связи донора (предположительно индия) определена как $63.2 \mathrm{meV}$ [18]. Показано, что линия $I_{9}$, как и остальные линии связанных экситонов на донорах, подчиняется правилу Хайнса с коэффициентом $\sim 0.3$ (энергия локализации $19.2 \mathrm{meV})$.

Трудно предполагать, что возникающая после облучения в ФЛ пленок $\mathrm{ZnO}$ новая линия есть линия излучения экситона, локализованного на индии. Естественнее думать о создании под действием мощного УФ-облучения новых или увеличении концентрации либо перезарядке присутствующих центров локализации экситонов. Об увеличении концентрации дефектов в облученных пленках свидетельствует некоторое уменьшение интенсивности их ФЛ по сравнению с исходной. Учитывая зависимость интенсивности новой линии от интенсивности возбуждения нельзя также исключить и проявления нелинейных эффектов в экситонных спектрах. Примечательно, что в исследуемую спектральную область

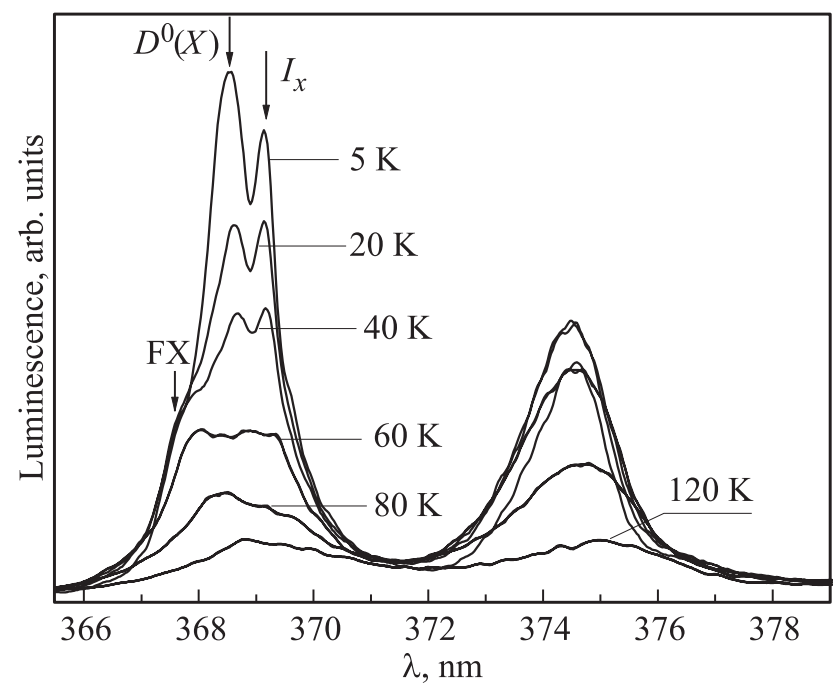

Рис. 4. Спектры ФЛ облученной азотным лазером пленки $\mathrm{ZnO}$ $(d=10 \mathrm{~nm})$ при возбуждении Не-Сd-лазером при различных температурах.

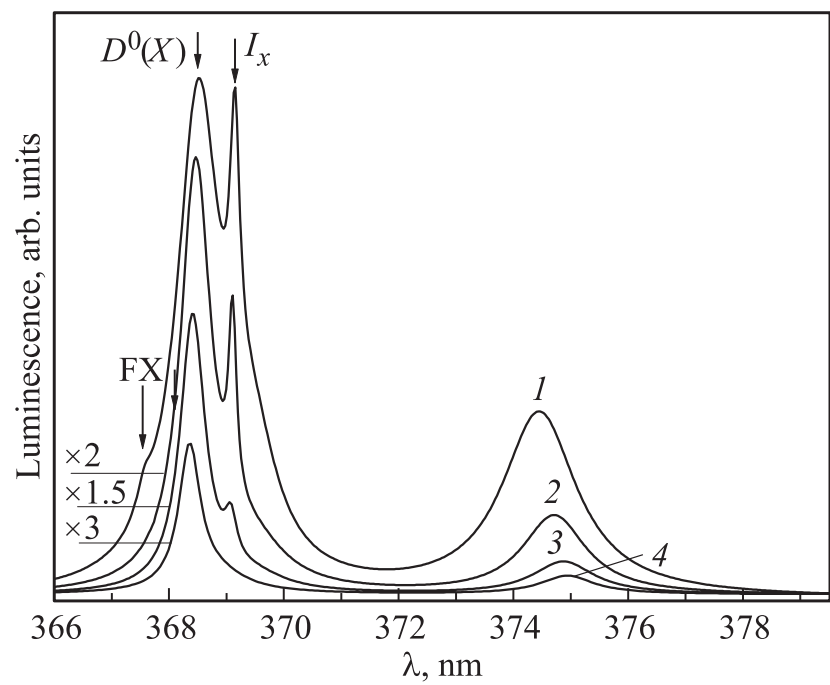

Pис. 5. Спектры ФЛ облученной азотным лазером пленки $\mathrm{ZnO}$ $(d=10 \mathrm{~nm})$ при $T=5 \mathrm{~K}$ и различных плотностях возбуждения $\mathrm{He}-\mathrm{Cd}$-лазером. Кривая 1 соответствует максимальной плотности $\left(0.3 \mathrm{~kW} / \mathrm{cm}^{2}\right)$.

попадает излучение связанного на дефекте биэкситона (полоса $B M_{3}, 3.3556 \mathrm{eV}, 369.4 \mathrm{~nm}$ ) [20]. Спектральное положение $I_{x}$ хорошо совпадает с положением полосы $B M_{3}$. О природе центра, на котором локализуется экситонная молекула, данные отсутствуют. Нелинейная зависимость интенсивности линии $I_{x}$ от интенсивности возбуждения допускает возможность ее интерпретации излучательным распадом биэкситона на фотогенерированном дефекте. Сравнительно невысокая плотность воз-

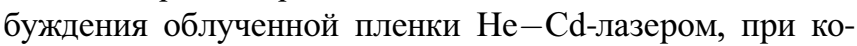
торой наблюдается возникновение обсуждаемой линии, вызывает сомнения в такой интерпретации. С другой 
стороны, в пользу биэкситонной версии может свидетельствовать ее появление при высоком уровне возбуждения третьей гармоникой титан-сапфирового лазера. Дальнейших исследований требует изучение природы фотогенерируемых центров, на которых может связываться биэкситон.

\section{4. Заключение}

При комнатной температуре изучены спектры ФЛ порошков и пленок $\mathrm{ZnO}$ при непрерывном УФ-облучении в многократных циклах вакуум-атмосфера. Показано, что в каждом цикле при вакуумировании образца наблюдается увеличение интенсивности экситонной люминесценции и ослабление излучения в области ЗП. Установлено, что с каждым следующим циклом амплитуды изменения интенсивностей экситонного излучения при сменах среды увеличиваются. Напротив, для зеленой полосы разность интенсивностей в вакууме и атмосфере становится меньше, при этом в основном за счет уменьшения сигнала в вакууме. Наблюдаемые эффекты связываются с процессами фотодесорбции и фотоадсорбции и, как следствие, с изменением загиба зон на поверхности. Новая линия излучения $(369.3 \mathrm{~nm})$ обнаружена в ФЛ-пленок при $T=5 \mathrm{~K}$ после облучения их интенсивным УФ $(3.68 \mathrm{eV})$ светом. Обсуждается возможность отнесения указанной линии к излучению биэкситона, связанного на дефектах, индуцированных мощной УФ-засветкой.

Авторы выражают благодарность сотрудникам ресурсного центра СПбГУ „Инновационные технологии композитных наноматериалов“. Авторы признательны Р.В. Григорьеву за содействие в подготовке настоящей публикации.

\section{Список литературы}

[1] C.F. Klingshirn, Bruno R. Meyer, A. Waag, A. Hoffmann, J. Geurts. Zinc Oxide Springer, Germany (2010). 359 c.

[2] А.С. Батырев, В.А. Киселев, Б.В. Новиков, А.Е. Чередниченко. Письма в ЖЭТФ 39, 459 (1984).

[3] V.V. Travnikov, A. Freiberg, S.F. Savikhin. J. Lumin. 47, 107 (1990).

[4] S. Kuehn, S. Friede, S. Sadofev, S. Blumstengel, F. Henneberger, T. Elsaesser. Appl. Phys. Lett. 103, 191909 (2013).

[5] J.P. Richter, T. Voos, D.S. Kim, R. Scholz, M. Zacharias. Nanotechnology 19, 11, 305202 (2008).

[6] D. Wang, N. Reynolds. ISRN Condens. Matter Phys. 2012, 950354.

[7] A. van Dijken, E.A. Meulenkamp, D. Vanmaekelbergh, A. Meijerink. J. Phys. Chem. B 104, 4355 (2000).

[8] И.Х. Акопян, М.Э. Лабзовская, А.А. Лисаченко, Б.В. Новиков, А.Ю. Серов, В.В. Титов, Н.Г. Философов. ФТТ 58, 1709 (2016).

[9] M.E. Labzovskaya, I.Kh. Akopyan, B.V. Novikov, A.Yu. Serov, N.G. Filosofov, L.L. Basov, V.E. Drozd, A.A. Lisachenko. Phys. Procedia 76, 37 (2015).
[10] H. Idriss, M.A. Barteau. J. Phys. Chem. B 96, 3382 (1992).

[11] D.W. Bahnemann, C. Kortmann, M.R. Hoffmann. J. Phys. Chem. 91, 3789 (1987).

[12] П.О. Артамонов, А.А. Лисаченко. Хим. физика 11, 344 (1992).

[13] D. Tainoff, B. Masenelli, P. Melinon, A. Belsky, G. Ledoux, D. Amans. C. Dujardin, N. Fedorov, P. Martin. Phys. Rev. B 81, 115304 (2010).

[14] M. Shirra, R. Schneider, A. Reiser, G.M. Prinz, M. Feneberg, J. Biskupek, U. Kaiser, C.E. Krill, K. Thonke, R. Sauer. Phys. Rev. B 77, 125215 (2008).

[15] Y.M. Lu, X.P. Li, P.J. Cao, S.C. Su, F. Jia, S. Han, W.J. Liu, D.L. Zhu, X.C. Ma. J. Spectroscopy, 797232 (2013).

[16] D.C. Look, D.C. Reynolds, C.W. Litton, R.L. Jones, D.B. Eason, G. Cantwell. Appl. Phys. Lett. 81, 1830 (2002).

[17] F.X. Xiu, Z. Yang, L.J. Mandalapu, J.L. Liu. Appl. Phys. Lett. 88, 152116 (2006).

[18] B.K. Meyer, H. Alves, D.M. Hofmann, W. Kriegsels, D. Forster, F. Bertram, J. Christen, A. Hofmann, M. Strassburg, M. Dworzak, U. Haboeck. Phys. Status. Solidi B 241 (2004).

[19] D.C. Reynolds, C.W. Litton, T.C. Collins. Phys. Rev. 140, A1726 (1965).

[20] A. Yamamoto, K. Miyamia, T. Goto, H.J. Ko, N. Yao. Phys. Status Solidi B 229, 871 (2002). 